\title{
Design and Tests of Prestressed Concrete Beams
}

\author{
JEAN-MARC FRANSSEN
}

Research Associate of the National Fund for Scientific Research (Belgium)

\section{ALOÏS BRULS}

Chargé de cours Trasenster

University of Liege

Dpt. Ponts et Charpentes

6, Quai Banning

B-4000, Liege, Belgium

\begin{abstract}
A prestressed TT beam had been designed considering the ultimate limit state of bending, and considering a temperature distribution given by a graph which was valid for a section with a similar shape. When tested in a furnace, it proved to have a fire resistance of only 79 minutes instead of the 2 hours foreseen by the calculation. An investigation was made, with the help of numerical modelling, to explain the reasons of the failure and to design a new specimen. Some modifications were introduced to increase the resistance to bending forces, to shear forces and to the slip of the tendons. A modified specimen behaved satisfactory in a second test.

The formula proposed in Eurocode 2 for the shear resistance of reinforced concrete elements at ambiant temperature has been adapted for the elevated temperature situation and its application allowed to accurately predict the failure mode observed in the first test.
\end{abstract}

KEYWORDS: simulation, prestress, test, fire.

\section{INTRODUCTION}

In the city of Namur, the capital of the Walloon region in Belgium, the open air main railway station is like a knife cut in the city, separating the centre of the town from its northern quarters. In order to create a link between the two separated parts of the city, as well as to valorise an important surface, it was decided to cover the railway by a slab which should be able to support the later addition of 3 levels high buildings. The surface of the slab is $140 \times 70$ 
$=9800 \mathrm{~m}^{2}$. The job was awarded to a Belgian contractor who bought the prestressed elements from a Dutch company. It was specified in the contract that the elements should have an ISO fire rating of 2 hours, and that it should be proved by experimental tests.

This paper explains the problems which were encountered and the solutions which were retained in 2 successive design and 2 experimental tests made on the elements, until the last one proved to be successful.

\section{FIRST ULTIMATE STATE DESIGN}

The elements are simply supported TT prestressed beams with a total length of $11477 \mathrm{~mm}$ and a clear span of $11230 \mathrm{~mm}$. The prefabricated elements have a width of $2400 \mathrm{~mm}$, a depth of $700 \mathrm{~mm}$ and will receive a decking of in situ concrete which has an average thickness of 80 $\mathrm{mm}$, see Fig. 1. Each of the 2 webs contains 9 tendons of $100 \mathrm{~mm}^{2}$. The dead load is 12.95 $\mathrm{kN} / \mathrm{m}$ and the live load in case of fire is $32.4 \mathrm{kN} / \mathrm{m}\left(13.5 \mathrm{kN} / \mathrm{m}^{2}\right)$. The characteristic material properties are:

Concrete of the decking

Concrete of the elements

Tendons

$$
\begin{aligned}
& \mathrm{R}_{\mathrm{wk}}^{\prime}=22.5 \mathrm{Mpa} \\
& \mathrm{R}_{\mathrm{wk}}^{\prime}=58 \mathrm{Mpa} \\
& \mathrm{f}_{\mathrm{yk}}=1860 \mathrm{Mpa}
\end{aligned}
$$

The ultimate state bending capacity of the section was evaluated, similarly as it could be done at $20^{\circ} \mathrm{C}$, with the exception that the yield strength of the tendons was decreased to account for the elevation of temperature. In a preliminary calculation, the temperature of the tendons after 2 hours was estimated from $\S 8.3 .2 .1 .2$. of the CEB recommendations [1]. A table gives the temperatures at different locations in a $160 \times 320 \mathrm{~mm}^{2}$ concrete beam. The lower tendon, \#1, having a temperature of roughly $700^{\circ} \mathrm{C}$ was safely neglected.

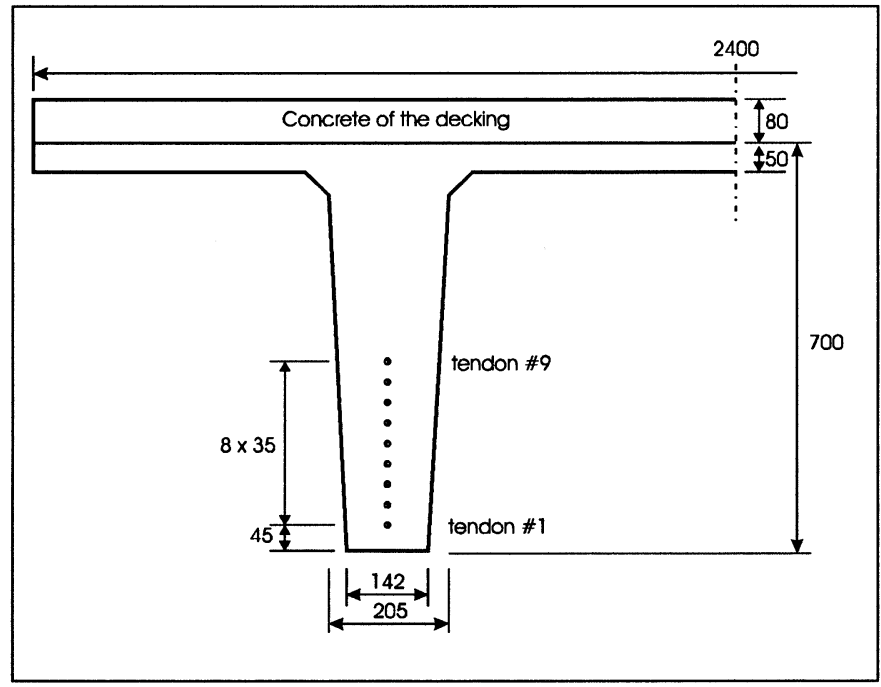

FIGURE 1 : half section in the elements. 
The next tendons had temperatures slowly decreasing from $560^{\circ} \mathrm{C}$ for $\# 2$ to $415^{\circ} \mathrm{C}$ for $\# 7$, due to the fact that their distance from the lower face of the web increases when passing from one tendon to the next one. Tendons \#8 and \#9 were inadequately given the temperatures of $330^{\circ} \mathrm{C}$ and $190^{\circ} \mathrm{C}$ respectively because the designer, not very familiar with the use of this table, was not aware that the table has been established for a beam in contact with air at $20^{\circ} \mathrm{C}$ on its upper face, i.e. at a distance of $320 \mathrm{~mm}$ from the lower face. This is by far not the case for tendon \#9 of the tested beam located at a distance of $455 \mathrm{~mm}$ from the upper face.

In a second version of the note, it was decided that the information from Eurocode $2:$ Part 1-2 [2] would be used. Figure A.2. of this document gives the isotherms in the lower $100 \mathrm{~mm}$ of a concrete beam with a width of $160 \mathrm{~mm}$, see Fig. 2 . Tendon \#1 was safely neglected because having a temperature of $700^{\circ} \mathrm{C}$. Tendon $\# 2$ has a temperature of $500^{\circ} \mathrm{C}$. Tendons $\# 3$ to \#9 were supposed to have a temperature of $390^{\circ} \mathrm{C}$, which is in fact an extrapolation of the figure. Finally the ultimate bending capacity was based on tendons \#2 to \#9 supposed to have a uniform temperature of $390^{\circ} \mathrm{C}$. The yield strength of steel was supposed to vary with temperature according to clause 3.3.5., Fig. 3.3 of Eurocode 2: Part 1-2 given for prestressing steel wires and strands (cold worked) :

$\frac{f_{y}(\Theta)}{f_{y}}=\frac{650-\Theta}{500}=\frac{650-390}{500}=0.52$

The effective yield strength being fixed at $0.52 \times 1860=967 \mathrm{Mpa}$, the moment of rupture was calculated as $820 \mathrm{kNm}$, greater than the required resistance : $715 \mathrm{kNm}$. No provision was taken to verify failure modes other than bending. This means that, except at the ends of the elements, the very minimum section of stirrups was placed, i.e. $5 \mathrm{~mm}$ bars every $300 \mathrm{~mm}$ placed in each web of the prefabricated element, not extending into the concrete decking.

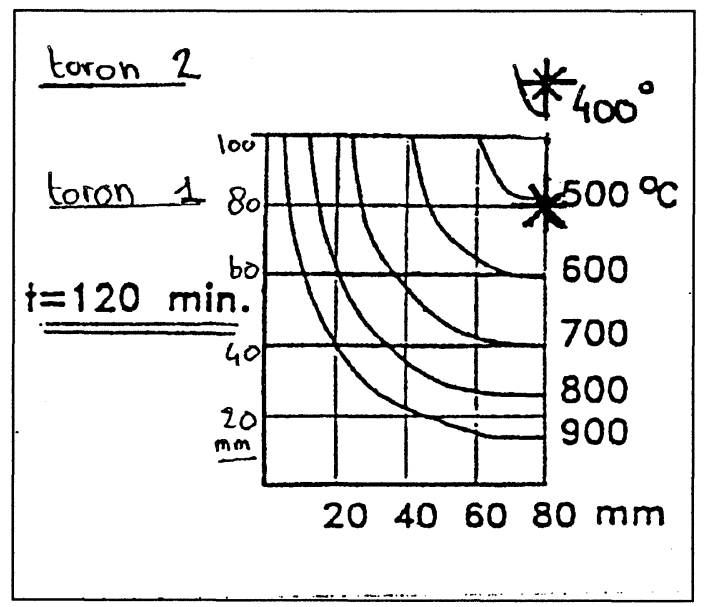

FIGURE 2 : temperature distribution considered. 


\section{FIRST EXPERIMENTAL TEST}

As defined in the contract between the contractor and the S.N.C.B., national railway company, a specimen was tested at the Laboratorium voor Aanwending der Brandstoffen en WarmteOverdracht of the University of Gent. Due to the limited length of the furnace, a specimen of 7 $000 \mathrm{~mm}$ was cut from an element and placed in the furnace, with a clear span of $6500 \mathrm{~mm}$. Two point loads of $233.8 \mathrm{kN}$ were applied, each of them at a distance of $2750 \mathrm{~mm}$ from a support which, associated to the dead load, created a maximum bending moment of $711 \mathrm{kNm}$ similar to the moment acting on the real elements. The maximum shear force was $276 \mathrm{kN}$, i.e. $8 \%$ more than the $255 \mathrm{kN}$ acting in reality. Figure 3 shows that the shape of the shear diagram in the test was more severe than the shape supported by the real specimen because a longer part of the tested beam is submitted to an important shear force whereas the shear force decreases rapidly in the real beams.

During the test, no significant degree of spalling could be observed through the windows of the furnace. On the contrary to what is usually observed in slabs or in beams with less depth, the deflection did not increase significantly during the first minutes of the test. The maximum deflection remained lower than $50 \mathrm{~mm}$ during the first hour. Important horizontal cracks, with an opening of several millimetres, were observed at the junction between the webs and the flanges. It was discovered after the test that those cracks did not extend more than $500 \mathrm{~mm}$ in the furnace, see Fig. 4. The limited deflection as well as the horizontal cracks are due to the different pattern of the isotherms, vertical in the webs and horizontal in the deck, see Fig. 5. The webs are elements which have an important stiffness and which are not submitted to the vertical thermal gradients which could cause a vertical deflection. The deck is an element submitted to a severe vertical thermal gradient and would deform as a circle, if not for the presence of the webs.

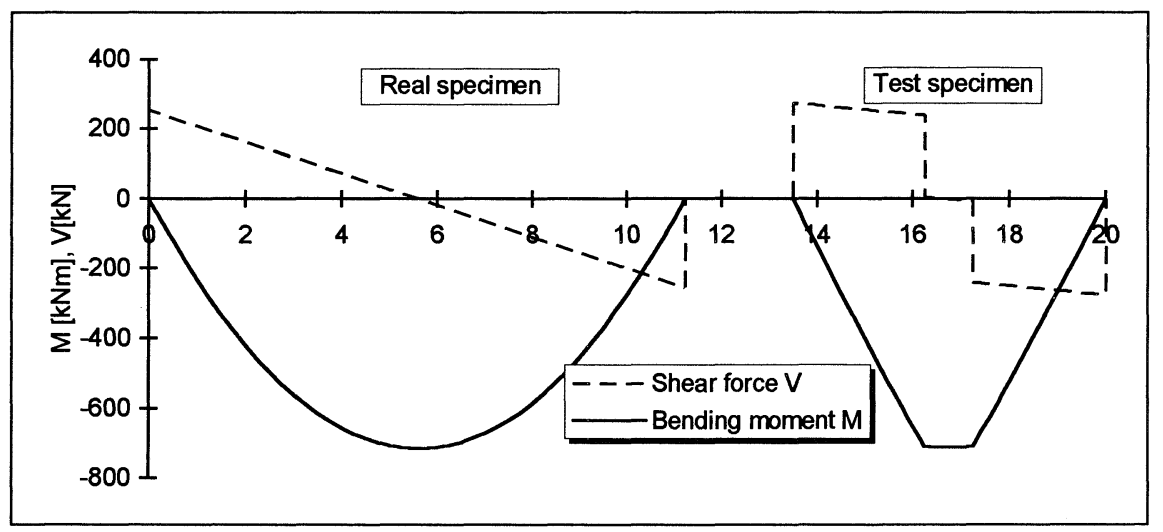

FIGURE 3 : comparison between test and real specimen. 


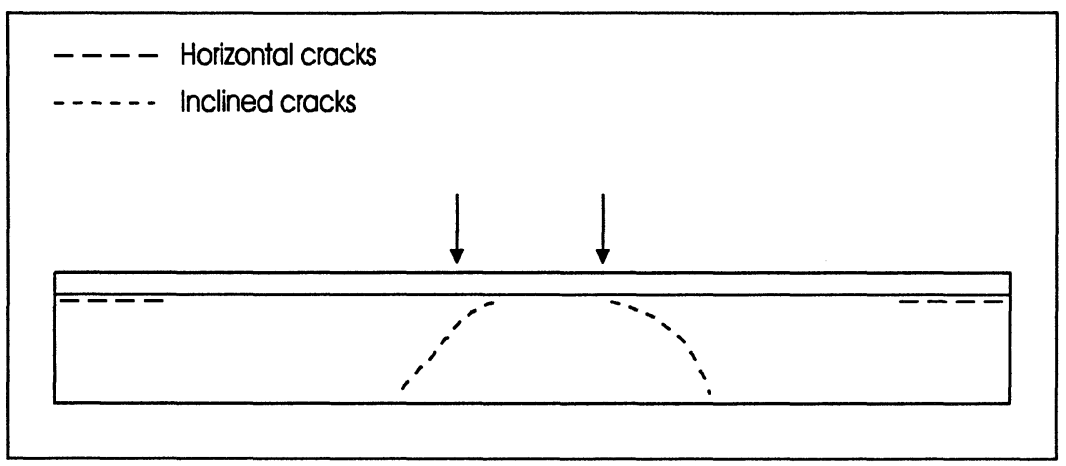

\section{FIGURE 4 : crack pattern.}

After 60 minutes, the deflection started to increase and reached $90 \mathrm{~mm}$ after $75 \mathrm{~min}$. After 76 minutes some important inclined cracks were observed in the webs through the windows of the furnace. The deflection accelerated to reach $200 \mathrm{~mm}$ after 79 minutes when the load could not be maintained.

It was observed after the test that the tendons in both webs had suffered some slip and had been drawn into the beam. The magnitude of the penetration was in the order of magnitude of $10 \mathrm{~mm}$. From a destructive investigation on the specimen, it appeared that the webs had been cracked along a vertical plane passing through the tendons. The contact between the concrete matrix and the tendons was not perfect in the vertical plane of the tendons due to the fact that the diameter of the aggregates was too large in comparison to the distance between the tendons.

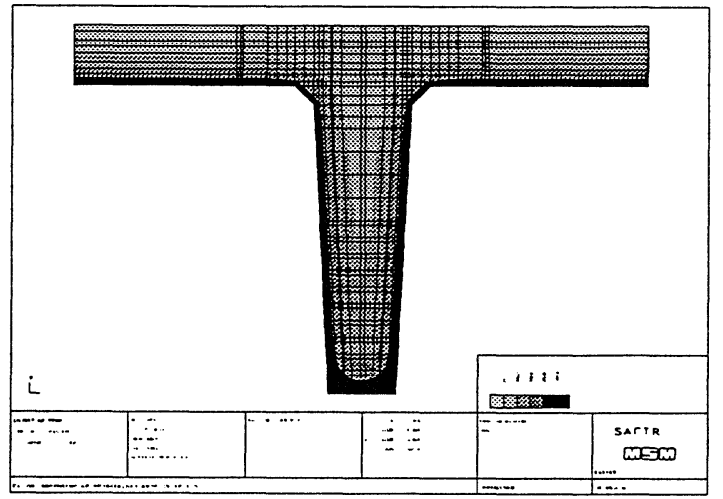

FIGURE 5 : calculated isotherms after 60 minutes. 
The authors had the opportunity to be involved in the analysis of this case and the first action was to evaluate more precisely the temperature distribution in the section, particularly in the web with its non uniform width. This thermal calculation was made with the non linear thermomechanical code SAFIR developed at the University of Liege. The pattern of the isotherms after 60 minutes is shown on Fig. 5 .

A new ultimate state design based on the bending capacity corresponding to the isotherms which had been numerically computed lead to a fire resistance time of 97 minutes.

A complete non linear analysis of the test by the computer program SAFIR, using here a Bernoulli beam finite element, leads to a fire resistance of 91 minutes. The evolution of the deflection measured in the test and calculated by the numerical code, in the hypothesis of a bending failure mode, is plotted on Fig. 6 . From this figure it could be concluded that:

1. even if no other phenomenon than bending had caused failure, the fire resistance time could not have been more than 91 or at best 97 minutes,

2. failure must have been caused by another failure mode because the fire resistance time obtained from the experimental test was only 79 minutes.

A shear failure mode was suspected because of the shape and position of the inclined cracks in the webs, because the shear reinforcement was almost non-existent and because the thermal strains could create tension in the web, thus annihilating the capacity of the concrete of the web to transmit shear forces.

It is of course possible to draw the longitudinal stress distribution in different cross sections and at different moments in the test, and thus to identify the zones which are in tension, but it is very difficult to derive quantitative conclusions from these drawings.

Fig. 7 shows the evolution of the stress in the 9 tendons as calculated if no slip had occurred. Note that in this graph, the time scale before the beginning of the fire test has been artificially modified in order to present the results in a more convenient way:

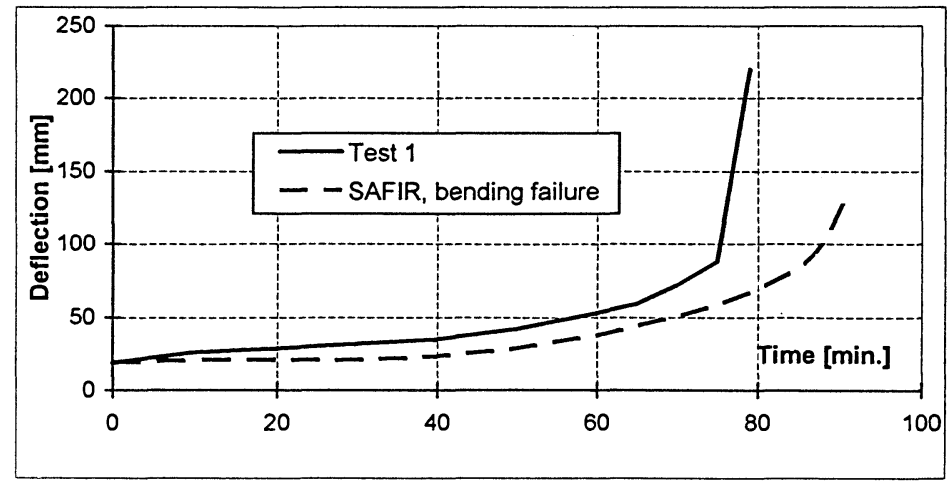

FIGURE 6 : evolution of the deflection in test 1. 


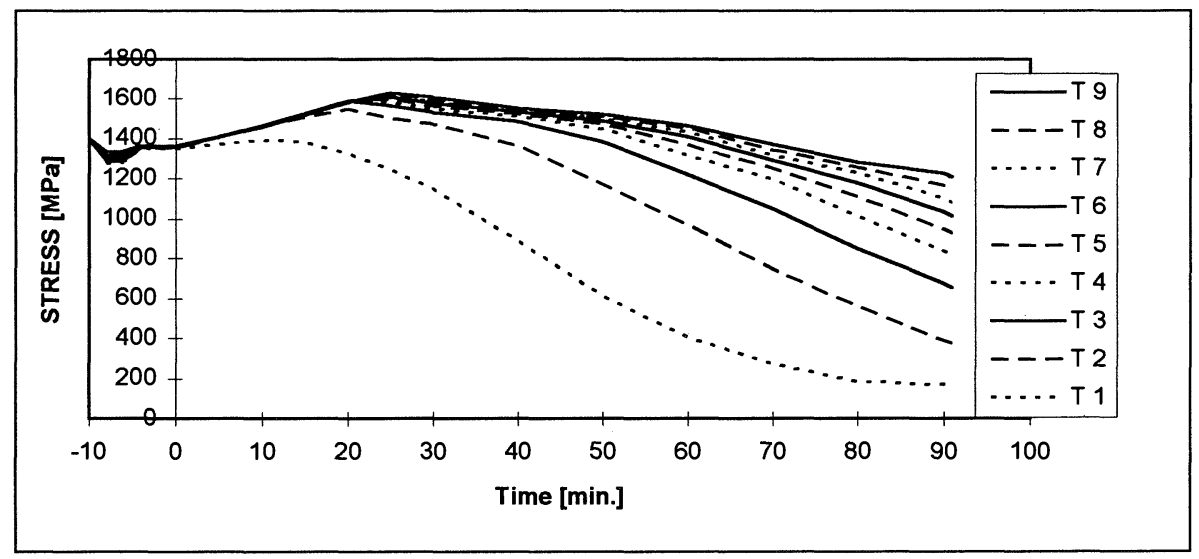

FIGURE 7 : stresses in the tendons.

$t=-10$ minutes corresponds to the time before the prestress load is transferred to the beam. $\sigma$ $=1400 \mathrm{Mpa}$ in all the tendons.

$t=-8$ minutes corresponds to the moment when the prestress load has been transferred to the beam, simultaneously in all the tendons. Although the dead weight is now supported, the deflection is upward and the stresses in the tendons decrease because of elastic shortening of the beam.

$t=-6$ minutes corresponds to the moment when a small additional load is introduced by the dead weight of the in situ concrete. The stresses in the tendons are hardly modified.

$t=-4$ minutes corresponds to the moment when the loads are introduced by the hydraulic jacks. The concrete of the decking is now able to take its share of the loading.

Nothing happens until $\mathrm{t}=0$ minute. The shrinkage of concrete is neglected in the calculation.

When the test starts, the stresses increase during the first 20 minutes due to the effect of thermal gradients, then decrease as the heat enters into the web and the reduction of the yield strength is becoming overwhelming in comparison to the thermal stresses. At the beginning of the test, the total prestressing load is $1222 \mathrm{kN}$ in each web. It reaches the maximum of 1400 $\mathrm{kN}$ after 20 to 25 minutes, is again at $1222 \mathrm{kN}$ after 50 minutes and decrease to $740 \mathrm{kN}$ after 90 minutes.

In order to investigate in a quantitative way the ultimate shear resistance of the beam, the method proposed in Eurocode 2 - Part 1-1 [3] for beams at room temperatures was adapted to take into account the effects of elevated temperatures. According to [3], the shear resistance is made of 3 different contributions.

Contribution of the steel strirrups. This contribution is given by equation (2).

$V_{s}=A_{s w} f_{y w d} \frac{0.9 d}{s}$

where $V_{s}$ is the contribution of the stirrups to the shear resistance, 
$A_{s w}$ is the section area of the stirrups,

$f_{y w d}$ is the design yield strength of the steel of the stirrups,

$d \quad$ is the effective depth of the section, distance between the longitudinal re-bars in tension and the opposite side of the section, and

$s \quad$ is the spacing between the stirrups.

In case of fire, $f_{y w d}$ has to be replaced by $f_{y w k}(\theta)$, the characteristic value of the yield strength at the temperature reached in the stirrups. For comparisons with an experimental test, the mean value of the yield strength should be used, but this data was not available. In a constant width web, the temperature of the stirrup is fairly constant. With the variations in width existing in this case, the temperature is slightly higher in the lower and thinner zone of the web. The temperature in the stirrups was taken at mid level of the reinforcing tendons, i.e. at the level of tendon \#5. Fig. 8 shows that this contribution was not important in the first tested element due to the small amount of vertical reinforcing placed, for ambiant rather than elevated temperature.

Contribution of the prestressing. For beams with an axial force, this is given by equation (3):

$V_{R d 1, p}=0.15 \sigma_{c p} b_{w} d$

where $\quad V_{R d 1, p}$ is the contribution provided by the axial force,

$b_{w} \quad$ is the minimum width of the web, and

$\sigma_{c p}=N_{S d} / A_{c}$

with $N_{S d}$ the axial force, and

$A_{c} \quad$ the cross sectional area.

In case of fire, the width of the web has been divided into several parts, namely 15 parts corresponding to the 15 vertical layers of finite elements chosen for the discretisation. Here also, the values were taken at the level of the level of the center of gravity of the tendons. $\sigma_{c p}$ is taken as the longitudinal stress calculated in each element by the finite non linear code,

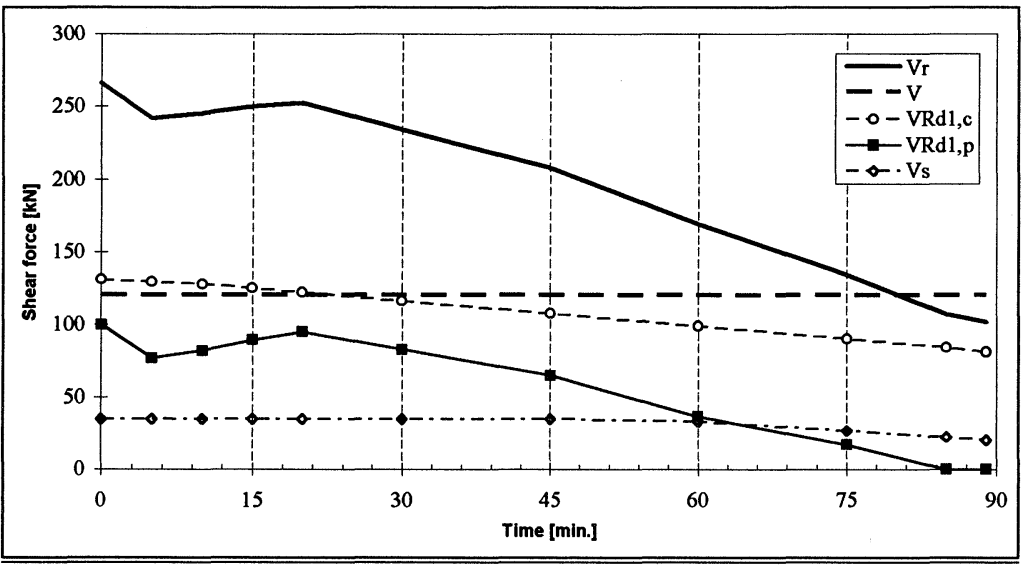

FIGURE 8 : evolution of the shear resistance during the first test. 
taking into account the effect of prestressing, of thermal strains, of applied loads and of temperature dependent stress strain relationships. In the elements where tension has caused cracking, the contribution is nul. Equation (4) thus gives the corresponding formula at elevated temperature:

$$
V_{R d 1, p}=0.15 d \sum_{i} \sigma_{l, i} b_{i}
$$

where $b_{i} \quad$ is the width of finite element $i$, with $\sum_{i} b_{i}=b_{w}$, and

$\sigma_{l, i} \quad$ is the time dependent longitudinal stress in finite element $i$.

It can be seen on Fig 8 that this contribution is important at ambiant temperature but decreases rather quickly during the test, as a consequence of the thermal stresses and of the decrease of the prestressing force, see Fig. 7.

Contribution of the concrete. This contribution, coming from the shear resistance of the concrete as well as from the action of the longitudinal re-bars is given by equation 5 :

$$
\begin{aligned}
& V_{R d 1, c}=\tau_{R d} k(1.2+40 \rho l) b_{w} d \\
& \text { where } \tau_{R d}=0.035 f_{c k}^{2 / 3} \quad f_{c k} \text { in } \mathrm{MPa} \\
& k=1.6-d \geq 1 \quad d \text { in } \mathrm{m} \\
& \rho l=\frac{A_{s l}}{b_{w} d} \\
& A_{s l} \quad \text { is the cross sectional area of longitudinal reinforcing. }
\end{aligned}
$$

In case of fire, equation 5 is modified in this way:

$$
\begin{aligned}
& V_{R d 1, c}=k(1.2+40 \rho l) d \sum_{i} b_{i} \tau_{k, i}(\theta) \\
& \text { where } \tau_{k, i}(\theta)=1.5 \times 0.035 f_{c k}{ }^{2 / 3}(\theta)
\end{aligned}
$$

It must be underlined that the hypothesis hidden in equation 10 is that the shear resistance of concrete is less affected by the temperature than the compressive strength. Fig. 8 shows that this makes $V_{R d 1, c}$ decrease slower than the other components with time.

As a whole, the total shear resistance $\mathrm{Vr}$ decreases and becomes equal to the applied shear force after 80 minutes, very close to the observed fire resistance of 79 minutes. This seems to indicate that the Eurocode formula for the shear resistance is able, when modified as indicated above, to predict the shear resistance of prestressed elements submitted to fire.

\section{NEW DESIGN}

As it had been shown that a fire resistance rating of 2 hours could not be obtained, even if no other failure mode than bending appeared and if the element was thus able to develop the full bending capacity, some provision had to be taken to increase the ultimate bending capacity in case of fire exposure. An acceptable solution was to increase the width of the webs from 
140 to $200 \mathrm{~mm}$ and to replace the 9 tendons of the original design by 8 tendons located as shown on Fig. 9.

This solution has several advantages:

- the central distance between the 2 webs is maintained, which reduces to a minimum the cost of mould modifications;

- the lateral cover on the tendons is increased by $10 \mathrm{~mm}$, which delays their heating;

- in each web, the cost of 46 more litres of concrete per meter of length is counterbalanced by the fact that 1 meter of tendon is saved;

- the vertical cover of the lowest tendons is increased from 45 to $120 \mathrm{~mm}$, which allows them to participate to the resistance, even in case of fire;

- the tendons are no more located on the same vertical line as in the first design. The previous design created a predefined plane of cracking which can be very unfavourable for the bond between the tendons and the concrete;

- the distance between the tendons is increased from 35 to $40 \mathrm{~mm}$ which should ensure a better contact between tendons and concrete.

Other modifications were made in order to decrease the likelihood of slip between the tendons and the concrete. The diameter of the aggregates was reduced in order to improve the contact. The danger of this modification was that, because the composition of the concrete had been changed, it was not certain that the good behaviour with respect to spalling observed in the first test would be reproduced in the second test. In addition to that, each group of 4 tendons was surrounded by a steel spiral with a diameter of the steel bars of $8 \mathrm{~mm}$, a pitch of $75 \mathrm{~mm}$, and extending from the support up to a distance of $1000 \mathrm{~mm}$. These spirals have the effect to provide confinement to the concrete surrounding the tendons.

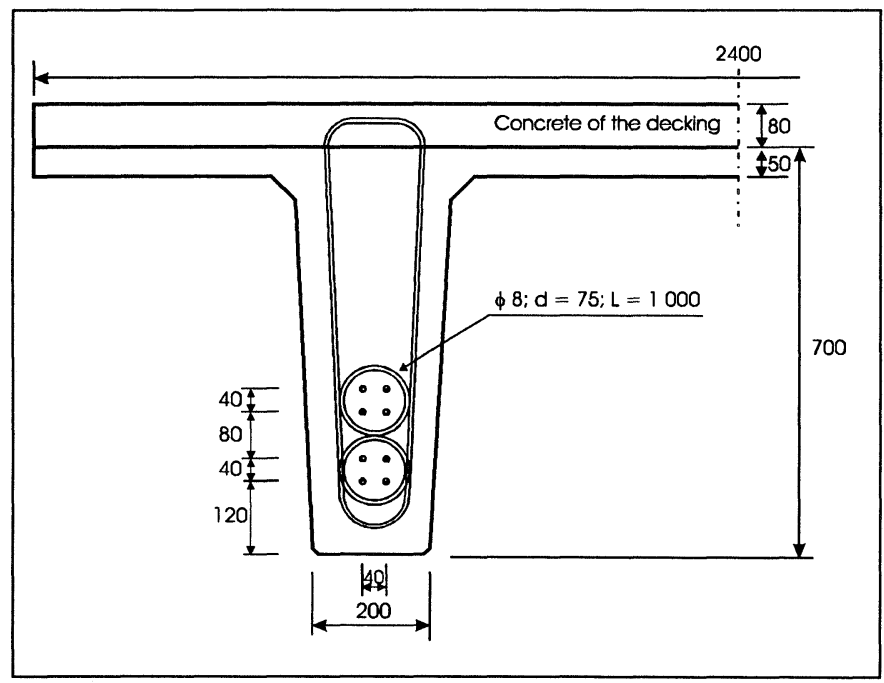

FIGURE 9 : new design. 


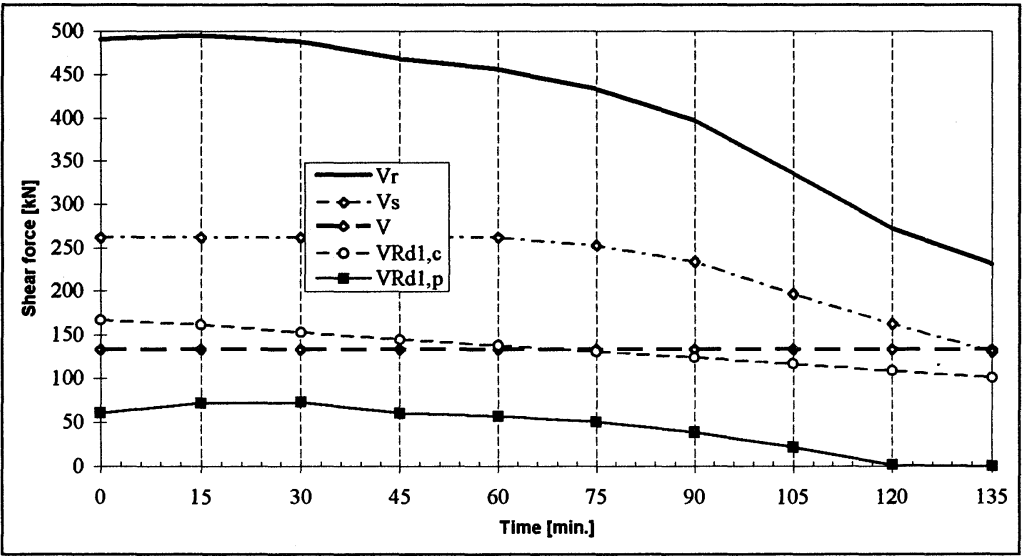

FIGURE 10 : evolution of the shear force in the new specimen.

Numerical analyses with the code SAFIR showed that the increase of the width of the web does not prevent tension to appear in the webs during the first 30 minutes. It was therefore decided that the shear forces should be resisted by passive re-bars. The stirrups are $\phi 8$ re-bars, extending into the concrete of the deck ( see Fig. 9), placed at a pitch from $100 \mathrm{~mm}$ close to the supports to $250 \mathrm{~mm}$ in the central part of the beam.

The evolution of the shear resistance, when estimated according to the procedure described above, is illustated on Fig. 10. As the model shows that the resistance due to the prestressing load is lost after 2 hours, and because of the uncertainties existing on the shear resistance of concrete, the specimen is designed in such a way that the vertical stirrups are sufficient during 135 minutes. This should be amply sufficient because the resistance to bending force of the new specimen was calculated as 130 minutes.

It must be understood that there was a very strict requirement for this test to be succesfull and that no unnecessary risk could be taken. It would be very usefull to perform additional test to determine whether the contribution provided by the shear resistance of concrete is reliable or not in case of fire.

\section{SECOND EXPERIMENTAL TEST}

A second experimental test was made in Gent on a specimen modified according to the recommendations explained in the previous paragraph. The specimen was cast on June 22 1995 and tested on October 161995 . The compressive strength of the concrete of the prefabricated element was $76.4 \mathrm{Mpa}$, measured at 28 days on $15 \mathrm{~cm}$ cubes. The specific mass of the concrete was $2422 \mathrm{~kg} / \mathrm{m}^{3}$.

It was observed during the tests that a lot of migrating moisture appeared on top of the concrete decking. The high moisture content, plus the high density of the concrete and the 
increased mass of the specimen, made it impossible to follow exactly the ISO curve in the furnace. The high moisture content also had the effect to cause some spalling in the webs which made some reinforcing bars visible, principally some stirrups and the 2 lower longitudinal passive bars. A slip of the tendons was observed at the ends of the beam, reaching $2 \mathrm{~mm}$ after 37 minutes and $4 \mathrm{~mm}$ after 80 minutes. The slip did not reach the $10 \mathrm{~mm}$ observed for the first test. Failure was defined by the laboratory as the moment when the deflection reached $1 / 30$ of the span, i.e. after 144 minutes. A correction was made according to ASTME119 [4] to take into account the fact that the fire curve in the furnace was less severe then what is normally prescribed. This led to a fire resistance of 121 minutes.

\section{CONCLUSIONS}

In order to reach a defined fire resistance time, a prestressed element must be adequately designed to sustain bending forces during the whole period of fire. If the geometry does not exactly correspond to one for which graphs or tables are given, a more refined numerical calculation of the temperature distribution may be necessary.

Other failure modes are also possible. Spalling is one, like in reinforced concrete elements. Shear failure or debonding are other possible failure modes, certainly more critical in prestressed elements than in reinforced concrete elements. The use of numerical simulations combined with good engineering judgement makes it possible to design appropriate details which prevent these failure modes. The recommendations given by Eurocode 2 for the shear resistance at ambiant temperature can be a usefull guide to estimate the shear resistance at elevated temperature, provided they are adapted as described in this paper.

\section{ACKNOWLEDGEMENTS}

This paper was written with the permission of VAN RYMENANT S.A., main contractor, and HURKS BETON N.V., supplier of the prestressed elements. The drawing of Fig. 5 has been made with the software DESFIN developped in the dpt. MSM of the Univ. of Liege.

\section{REFERENCES}

1. Design of concrete structures for fire resistance, Bulletin d'information $\mathrm{N}^{\circ} 145$, Comité Euro International du Béton, 1982.

2. Eurocode 2: Design of concrete structures. Part 1-2: Structural fire design, prENV 1992-1-2, CEN, October 1993.

3. Eurocode 2: Design of concrete structures. Part 1.2: General rules. Structural fire design. ENV 1992-1-2, CEN, Brussels, November 1995.

4. Standard Methods of the Fire Tests of Building Construction and Materials, Designation E11995a, ASTM, Philadelphia, 436-456, 1995. 